\title{
Brain region-specificity of palmitic acid-induced abnormalities associated with Alzheimer's disease Sachin Patil ${ }^{1}$, Deebika Balu${ }^{1}$, Joseph Melrose ${ }^{1}$ and Christina Chan ${ }^{* 1,2}$
}

Address: ${ }^{1}$ Department of Chemical Engineering and Material Science, Michigan State University, East Lansing, Michigan, USA and ${ }^{2}$ Department of Biochemistry and Molecular Biology, Michigan State University, East Lansing, Michigan, USA

Email: Sachin Patil - patilsac@msu.edu; Deebika Balu - baludeeb@msu.edu; Joseph Melrose - melrosej@msu.edu; Christina Chan* - krischan@egr.msu.edu

* Corresponding author

Published: 4 June 2008

BMC Research Notes 2008, I:20 doi:10.1 I86/1756-0500-I-20
Received: 3I March 2008

Accepted: 4 June 2008

This article is available from: http://www.biomedcentral.com/l756-0500/I/20

(C) 2008 Patil et al; licensee BioMed Central Ltd.

This is an Open Access article distributed under the terms of the Creative Commons Attribution License (http://creativecommons.org/licenses/by/2.0), which permits unrestricted use, distribution, and reproduction in any medium, provided the original work is properly cited.

\begin{abstract}
Background: Alzheimer's disease (AD) is a progressive, neurodegenerative disease mostly affecting the basal forebrain, cortex and hippocampus whereas the cerebellum is relatively spared. The reason behind this region-specific brain damage in $A D$ is not well understood. Here, we report our data suggesting "differential free fatty acid metabolism in the different brain areas" as a potentially important factor in causing the region-specific damage observed in $A D$ brain.

Findings: The astroglia from two different rat brain regions, cortex (region affected in $A D$ ) and cerebellum (unaffected region), were treated with $0.2 \mathrm{mM}$ of palmitic acid. The conditioned media were then transferred to the cortical neurons to study the possible effects on the two main, ADassociated protein abnormalities, viz. BACEI upregulation and hyperphosphorylation of tau. The conditioned media from palmitic-acid treated cortical astroglia, but not the cerebellar astroglia, significantly elevated levels of phosphorylated tau and BACEI in cortical neurons as compared to controls ( $47 \pm 7 \%$ and $45 \pm 4 \%$, respectively).

Conclusion: The present data provide an experimental explanation for the region-specific damage observed in AD brain; higher fatty acid-metabolizing capacity of cortical astroglia as compared to cerebellar astroglia, may play a causal role in increasing vulnerability of cortex in $A D$, while sparing cerebellum.
\end{abstract}

\section{Findings}

Alzheimer's disease (AD) is a progressive neurodegenerative disease, which affects basal forebrain, cortex and hippocampus, while cerebellum is relatively spared [1]. AD brain is characterized by extracellular deposits of amyloid beta $(A \beta)$ protein and intracellular accumulation of neurofibrillary tangles [1]. A $\beta$ protein is derived from the proteolysis of $\beta$-amyloid precursor protein (APP) by $\beta$ secretase (BACE1) and $\gamma$-secretase, BACE1 step being the rate-limiting step [2]. The aggregation of $A \beta$ leads to the formation of senile plaques, a characteristic feature of $\mathrm{AD}$ [1]. $A \beta$ aggregates exert toxicity to nerve cells and thus play a central role in $\mathrm{AD}$-associated neurodegeneration [1]. Neurofibrillary tangles, the other major characteristic of $\mathrm{AD}$ pathology, are composed of paired helical filaments of microtubule-associated tau protein, which is hyperphosphorylated in $\mathrm{AD}[3]$. The hyperphosphorylation of tau leads to the disruption of the cytoskeleton of neurons and their degeneration, thus playing an important role in AD pathology [1]. 
Epidemiological studies implicate that high fat diet confers a significant risk for development of $\mathrm{AD}$ and the degree of saturation of fatty acids is critical in determining the risk for AD [4]. These studies are further supported by various animal studies where mice fed high-fat-high cholesterol diet developed AD-like pathophysiological changes in their brain $[5,6]$. Furthermore, various vascular diseases such as diabetes mellitus, hypertension and obesity, which are characterized by increased levels of saturated free fatty acids (FFAs), pose a significant risk for developing $\mathrm{AD}$ [7-9]. Also, traumatic brain injury is an independent risk factor for $\mathrm{AD}[10]$, and is characterized by elevated levels of saturated fatty acids in the brain [11], with palmitic acid increasing from $\sim 60$ to $180 \mu \mathrm{M}$ and stearic acid from $\sim 50$ to $350 \mu \mathrm{M}$ [12]. Finally, apolipoprotein $\mathrm{E} 4$ (ApoE4) is an important genetic risk factor for $\mathrm{AD}$ and its risk may be further increased by diets rich in saturated fats [13].

Despite these data suggesting causal involvement of saturated fatty acids in AD pathogenesis, their potential role in causing the region-specific damage associated with $\mathrm{AD}$ pathology is not well studied. In the present study, we report our data suggesting "differential free fatty acid (FFA) metabolism in the different brain areas" as a potential causal factor behind the region-specific damage observed in $\mathrm{AD}$.

\section{Methods \\ Isolation and culture of neurons and astroglia from rat cortex}

Primary cortical neurons were isolated from one-day-old Sprague-Dawley rat pups and cultured according to the published methods as described by Chandler et al. [14]. The cells were plated on poly-l-lysine-coated, six-well plates at the concentration of $2 \times 10^{6}$ cells per well in fresh cortical medium [Dulbecco's Modified Eagle's Medium (DMEM, from Invitrogen, CA, USA) supplemented with $10 \%$ horse serum (Sigma, MO, USA), 25 mM glucose, 10 mM HEPES (Sigma), 2 mM glutamine (BioSource International, CA, USA), $100 \mathrm{IU} / \mathrm{ml}$ penicillin, and $0.1 \mathrm{mg} / \mathrm{ml}$ streptomycine]. To obtain pure neuronal cell cultures, the medium was replaced with the cortical medium supplemented with $5 \mu \mathrm{M}$ cytosine- $\beta$-arabinofuranoside (Arac, from Calbiochem, CA) after 3 days of incubation $\left(37^{\circ} \mathrm{C}\right.$, $5 \% \mathrm{CO} 2$ ). After 2 days, the neuronal culture was switched back to cortical medium without Arac. The experiments were performed on 6- to 7-day-old neuronal cells. To obtain primary cultures of cortical astroglia, the cortical cells from one-day-old Sprague-Dawley rat pups were cultured in DMEM/Ham's F12 medium (1:1), 10\% fetal bovine serum (Biomeda, CA, USA), $100 \mathrm{IU} / \mathrm{ml}$ penicillin, and $0.1 \mathrm{mg} / \mathrm{ml}$ streptomycine [15]. The cells were plated on poly-d-lysine coated, 6 -well plates at the concentration of $2 \times 106$ cells per well. Cells were grown for 8-10 days $\left(37^{\circ} \mathrm{C}, 5 \% \mathrm{CO} 2\right)$ and culture medium was changed every 2 days. Twenty-four hours prior to treatment with palmitic acid, the medium was changed to cortical neuronal cell culture medium.

\section{Isolation and culture of astroglia from rat cerebellum}

The enzyme digestion and trituration techniques were performed on the cerebellum tissue from 7-day-old rat pups, as described previously [16]. Briefly, dissected cerebellar tissue was placed in a cerebellar buffer solution containing $136.89 \mathrm{mM} \mathrm{NaCl}, 5.36 \mathrm{mM} \mathrm{KCl}, 0.34 \mathrm{mM}$ Na2HPO4, 0.44 mM KH2PO4, 5.55 mM dextrose, 20.02 $\mathrm{mM}$ Hepes, and $4.17 \mathrm{mM} \mathrm{NaHCO} 3, \mathrm{PH}$ 7.4. Cerebellar tissue was minced, transferred to $0.025 \%$ trypsin solution in cerebellar buffer, and incubated in water bath for 15 minutes at $37^{\circ} \mathrm{C}$. $0.04 \%$ DNase I solution in cerebellar medium (DMEM supplemented with 10\% horse serum, $25 \mathrm{mM} \mathrm{KCl}, 5 \mathrm{mg} / \mathrm{ml}$ insulin, $50 \mu \mathrm{M}$ GABA, $100 \mathrm{IU} / \mathrm{ml}$ penicillin, and $0.1 \mathrm{mg} / \mathrm{ml}$ streptomycine) was then added to inactivate trypsin. After the supernatant was collected from the trituration steps, the cells were separated from the debris into 4\% BSA solution in cerebellar buffer supplemented with $0.03 \% \mathrm{MgSO}$. Finally, the cells were plated onto poly-l-lysine coated 6-well culture dishes at a density of $2.0 \times 10^{6}$ cells $/ \mathrm{ml}$ in $3 \mathrm{ml}$ of fresh cerebellar medium. After 2 days, the media was switched to DMEM/ Ham's F12 medium (1:1) to obtain pure cultures of cerebellar astroglia. The astroglia cell cultures with approximately $95 \%$ purity were obtained after 8-10 days culture $\left(37^{\circ} \mathrm{C}, 5 \% \mathrm{CO} 2\right)$. Twenty-four hours prior to treatment with palmitic acid, the medium was changed to cortical neuronal cell culture medium.

\section{Western blot analyses}

For Western blotting, cells were washed three times with ice-cold TBS (25 mM Tris, $\mathrm{pH} 8.0,140 \mathrm{mM} \mathrm{NaCl}$, and 5 $\mathrm{mM} \mathrm{KCl}$ ) and lysed for $20 \mathrm{~min}$ by scraping into ice-cold lysis buffer. To extract membrane protein BACE1, lysis buffer containing $1 \%(\mathrm{v} / \mathrm{v})$ Nonidet P-40, $0.1 \%(\mathrm{w} / \mathrm{v})$ SDS, $0.5 \%(\mathrm{w} / \mathrm{v})$ deoxycholate, $50 \mathrm{mM}$ Tris, $\mathrm{pH} 7.2,150$ $\mathrm{mM} \mathrm{NaCl}, 1 \mathrm{mM} \mathrm{Na} 3 \mathrm{VO} 4$ and $1 \mathrm{mM}$ PMSF [all chemicals from Sigma] was used [17]. For phosphorylated tau, lysis buffer containing $1 \%(\mathrm{v} / \mathrm{v})$ Triton, $0.1 \%(\mathrm{w} / \mathrm{v})$ SDS, $0.5 \%$ $(\mathrm{w} / \mathrm{v})$ deoxycholate, $20 \mathrm{mM}$ Tris, $\mathrm{pH} 7.4,150 \mathrm{mM} \mathrm{NaCl}$, $100 \mathrm{mM}$ NaF, $1 \mathrm{mM}$ Na3VO4, 1 mM EDTA, 1 mM EGTA, and $1 \mathrm{mM}$ PMSF [all chemicals from Sigma] was used [18]. The total cell lysate was obtained by centrifugation at $12,000 \mathrm{rpm}$ for $15 \mathrm{~min}$ at $4^{\circ} \mathrm{C}$. The total protein concentration was measured by BCA protein assay kit from Pierce (Rockford, IL, USA). Equal amounts of total protein from each condition were run at $200 \mathrm{~V}$ on $10 \%$ SDS-PAGE gels (BioRad, CA, USA). The separated proteins were transferred to nitrocellulose membranes for $1 \mathrm{~h}$ at $100 \mathrm{~V}$ and incubated at $4^{\circ} \mathrm{C}$ overnight with the appropriate primary antibodies [1:1000 BACE1 (Chemicon, CA, USA), 
1:200 AT8 (Pierce Biotechnology, IL, USA), 1:2000 actin (Sigma)]. Blots were washed three times in PBS-Tween (PBS-T) and incubated with appropriate HRP-linked secondary antibodies (Pierce Biotechnology, IL, USA) diluted in PBS-T for $1 \mathrm{~h}$. After an additional three washes in PBS-T, blots were developed with the Pierce SuperSignal West Femto Maximum Sensitivity Substrate (Pierce Biotechnology) and imaged with the BioRad ChemiDoc.

\section{Data Analyses}

Data are shown as means \pm S.D. for three independent experiments. Student's t-test was used to evaluate statistical significances between different treatment groups. Statistical significance was set at $\mathrm{p}<0.05$.

\section{Results and Discussion}

Previously, we showed that saturated fatty acids, palmitic acid (PA) and stearic acid (SA), at pathological concentrations $(0.2 \mathrm{mM})$ have no direct effect on primary rat cortical neurons [19-21]. This may be attributed to the low capacity of primary neurons to take up and metabolize fatty acids [22]. The astroglia, in contrast, possess a relatively higher capacity to utilize fatty acids, leading to a significant upregulation in the de novo synthesis of ceramide when treated with saturated FFAs [21,22]. PA-induced ceramide synthesis in cortical astroglia plays a central role in causing tau hyperphosphorylation and BACE1 upregulation in cortical neurons, possibly through secretion of cytokines or other signaling molecules (e.g. nitric oxide) from astroglia [21]. Tau hyperphoshorylation and increased amyloidogenesis due to BACE1 upregulation leads to the formation of the two most important pathophysiological hallmarks of AD, neurofibrillary tangles and A $\beta$ plaques, respectively. Based on these data, which place "astroglial FFA metabolism" at the centre of the pathogenic cascade leading to $\mathrm{AD}$, we hypothesized that differential FFA metabolism by astroglia from different brain areas may be a deciding factor in the susceptibility of the different brain regions; the higher the FFA metabolic activity the greater the damage and vice versa. The hypothesis was based on the fact that the activity of fatty acyl-CoA synthetase (FACS) is $10 \times$ lower in cerebellum (unaffected region in $\mathrm{AD}$ ) as compared to the other affected brain regions [23]; FACS is the first enzyme involved in FFA metabolism, which converts fatty acid to fatty acyl-CoA, which is then utilized by the cells in anabolic (e.g. ceramide synthesis) or catabolic (e.g. $\beta$-oxidation) pathways [24]. Thus, under pathologically elevated levels of saturated FFAs, cerebellum may be less likely to be affected by abnormal FFA metabolism due to its lower activity level of FACS as compared to the other affected brain regions (e.g. cortex). To test this hypothesis, we treated cortical and cerebellar astroglia for 24 hours with equal concentration of saturated fatty acid, $0.2 \mathrm{mM} \mathrm{PA}$, or $4 \%$ bovine serum albumin (BSA, control) and then transferred the astroglia-con- ditioned media to cortical neurons. After 24 hours of treatment with astroglia-conditioned media, we checked the levels of phosphorylated tau and BACE1 in cortical neurons. The conditioned media from PA-treated cerebellar astroglia, did not affect levels of both phosphorylated tau and BACE1 in cortical neurons as compared to controls (Figure 1). The conditioned media from PA-treated cortical astroglia, on the other hand, induced significant tau hyperphosphorylation and BACE1 upregulation in cortical neurons as compared to the respective controls (47 and 45\%, respectively). These data support our hypothesis, further emphasizing potentially causal role of astroglial FFA metabolism in AD pathogenesis and regionspecific brain damage associated with it.

The major limitation associated with the present study may be the use of cortical and cerebellar astroglia isolated from different animals and by different techniques. The well-established protocols used in our studies for the isolation of rat cortical [14] and cerebellar [16] cells, required use of rat pups of different ages. For the isolation of rat cortical cells, embryonic [2] or very young, 1-2 day old [14] rat pups are preferred and thus 1-day old rat pups were used in our studies. The use of older rat pups for the isolation of rat cortical cells significantly decreases the viability and quality of the cells. On the other hand, 6-7 day old rat pups have been widely used for the isolation of cells from rat cerebellum $[16,25]$. The use of older rats for the isolation of cerebellar cells may be attributed to the fact that the cerebellum develops postnatally as compared with cortex [15]. Despite these differences, both cortical and cerebellar astroglia were allowed to proliferate and mature under similar conditions (cultured in the same medium for the same amount of time). Moreover, these confluent cultures of astroglia from both the brain areas were cultured in the same growth medium (cortical neuronal medium) 24 hours prior to treatment. Also, during the treatment period they were subjected to the same amount of PA in the same growth medium (cortical neuronal medium). Therefore, it is reasonable to compare the results obtained with cortical and cerebellar astroglia isolated from the different animals and by the different techniques.

\section{Conclusion}

To our knowledge, this is the first time any of the risk factors for AD, including saturated FFAs, have been shown to provide an experimental explanation for the region-specific damage observed in AD brain. These data warrant further in-depth investigation of the differential FFA metabolic activities in cortical and cerebellar astroglia, which may provide clues that may be translated into potential, novel targets for therapeutic intervention in $\mathrm{AD}$. 
(A)

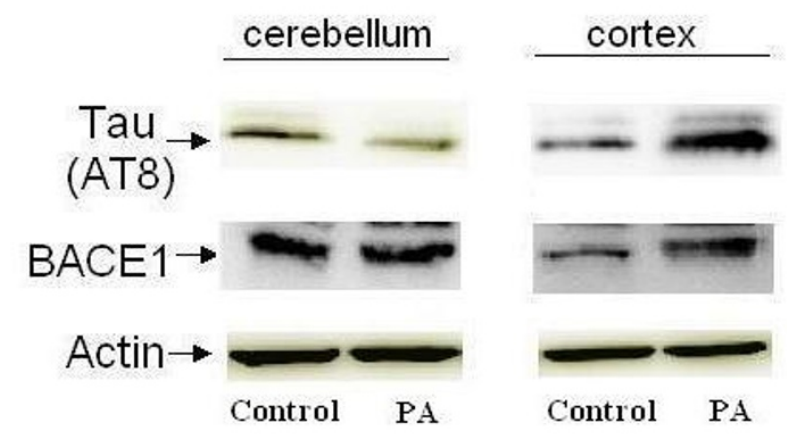

(B)
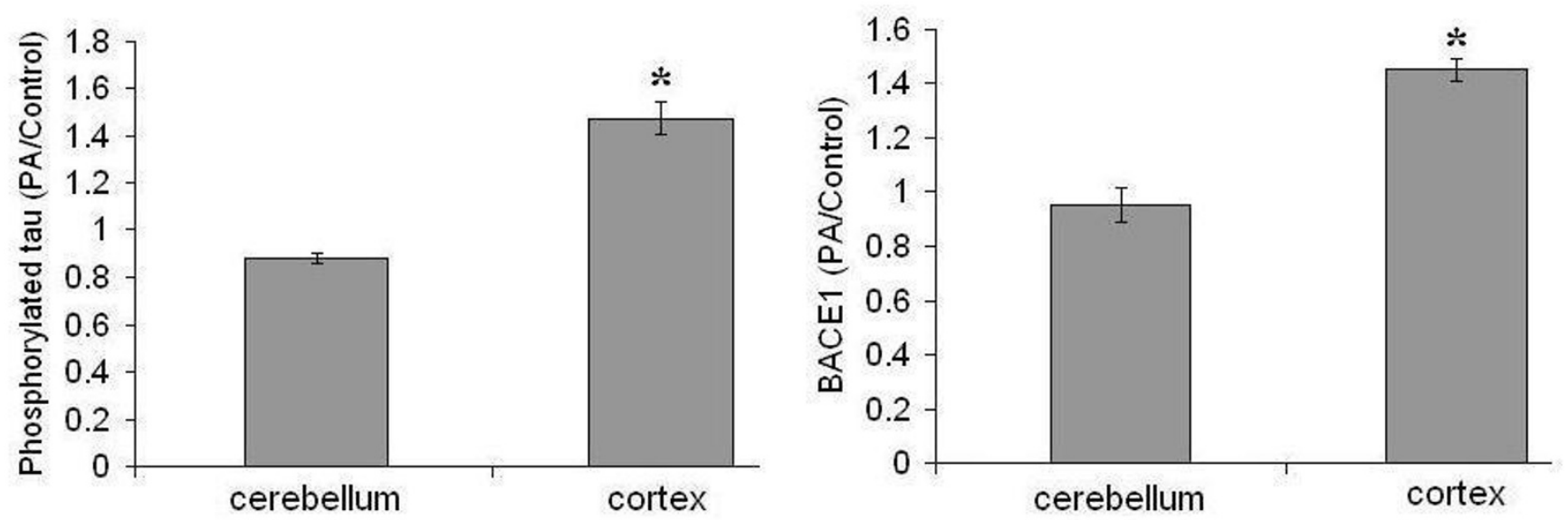

\section{Figure I}

Cortical, but not cerebellar, astroglia mediate FFA-induced tau hyperphosphorylation and BACE I upregulation in cortical neurons. Both cortical and cerebellar astroglia were treated for 24 hours with 0.2 mM of palmitic acid (PA) or $4 \%$ BSA (control), followed by transfer of the astroglia-conditioned media to cortical neurons (24 hours treatment). ( $\mathrm{A})$ Western blot analysis of hyperphosphorylated tau (AT8 antibody) and BACEI. $\beta$-actin is shown as a marker for protein loading. (B) Histograms corresponding to AT8 and BACEI blots represent quantitative determinations of intensities of the relevant bands, presented as the ratio of PA-treated to control. Data represent mean \pm S.D. of three independent experiments. Student's t-test was used for analyzing differences between two treatment groups $(* p<0.05$ compared with control).

\section{Competing interests}

The authors declare that they have no competing interests.

\section{Authors' contributions}

SP conceptualized the study, designed the study protocols and analyzed the collected data. DB and JM participated in the experimental work. DB performed isolation, culture and experimental treatment of primary brain cells. JM carried out western blotting. SP and CC drafted the manuscript. All authors reviewed and approved the final manuscript.

\section{Acknowledgements}

This work was funded in part by the MSU Foundation, the National Science Foundation (BES No. 0331297 and No. 042582I) the National Institutes of Health (IROIGM079688-0I), the Environmental Protection Agency
(RD8318470I), the Whitaker Foundation and Quantitative Biological Modeling Initiative (QBMI) at MSU.

\section{References}

I. Mattson MP: Pathways towards and away from Alzheimer's disease. Nature 2004, 430(7000):63I-639.

2. Cunha-Oliveira T, Rego AC, Cardoso SM, Borges F, Swerdlow RH, Macedo T, de Oliveira CR: Mitochondrial dysfunction and caspase activation in rat cortical neurons treated with cocaine or amphetamine. Brain Res 2006, I089(I):44-54.

3. Lee MS, Kwon YT, Li M, Peng J, Friedlander RM, Tsai LH: Neurotoxicity induces cleavage of p35 to p25 by calpain. Nature 2000, 405(6784):360-364.

4. Grant WB: Dietary links to Alzheimer's disease: 1999 update. J Alzheimers Dis 1999, I(4-5): 197-20I.

5. Levin-Allerhand JA, Lominska CE, Smith JD: Increased amyloidlevels in APPSWE transgenic mice treated chronically with a physiological high-fat high-cholesterol diet. J Nutr Health Aging 2002, 6(5):315-319. 
6. Oksman M, livonen H, Hogyes E, Amtul Z, Penke B, Leenders I, Broersen L, Lutjohann D, Hartmann T, Tanila H: Impact of different saturated fatty acid, polyunsaturated fatty acid and cholesterol containing diets on beta-amyloid accumulation in APP/ PSI transgenic mice. Neurobiol Dis 2006, 23(3):563-572.

7. Skoog I, Lernfelt B, Landahl S, Palmertz B, Andreasson LA, Nilsson L, Persson G, Oden A, Svanborg A: I5-year longitudinal study of blood pressure and dementia. Lancet 1996, 347(9009): | |4|-|| |45.

8. Arvanitakis Z, Wilson RS, Bienias JL, Evans DA, Bennett DA: Diabetes mellitus and risk of Alzheimer disease and decline in cognitive function. Arch Neurol 2004, 6 I(5):66 I-666.

9. Whitmer RA, Gunderson EP, Barrett-Connor E, Quesenberry CP Jr. Yaffe K: Obesity in middle age and future risk of dementia: a 27 year longitudinal population based study. Bmj 2005, 330(7504): 1360.

10. Guo Z, Cupples LA, Kurz A, Auerbach SH, Volicer L, Chui H, Green RC, Sadovnick AD, Duara R, DeCarli C, Johnson K, Go RC, Growdon $\mathrm{JH}$, Haines JL, Kukull WA, Farrer LA: Head injury and the risk of AD in the MIRAGE study. Neurology 2000, 54(6): | 3 | $6-1323$.

II. Homayoun P, Rodriguez de Turco EB, Parkins NE, Lane DC, Soblosky J, Carey ME, Bazan NG: Delayed phospholipid degradation in rat brain after traumatic brain injury. I Neurochem 1997, 69(I):199-205.

12. Lipton P: Ischemic cell death in brain neurons. Physiol Rev 1999, 79(4): $|43|-\mid 568$

13. Petot GJ, Traore F, Debanne SM, Lerner AJ, Smyth KA, Friedland RP: Interactions of apolipoprotein $E$ genotype and dietary fat intake of healthy older persons during mid-adult life. Metabolism 2003, 52(3):279-28I.

14. Chandler LJ, Newsom H, Sumners C, Crews F: Chronic ethanol exposure potentiates NMDA excitotoxicity in cerebral cortical neurons. J Neurochem 1993, 60(4):I578-I58I.

15. Pshenichkin SP, Wise BC: Okadaic acid increases nerve growth factor secretion, mRNA stability, and gene transcription in primary cultures of cortical astrocytes. J Biol Chem 1995 270( I I):5994-5999.

16. Marty MS, Atchison WD: Pathways mediating Ca2+ entry in rat cerebellar granule cells following in vitro exposure to methyl mercury. Toxicol Appl Pharmacol 1997, I47(2):319-330.

17. Wen Y, Onyewuchi O, Yang S, Liu R, Simpkins JW: Increased betasecretase activity and expression in rats following transient cerebral ischemia. Brain Res 2004, I 009( I-2): I-8.

18. Williamson R, Scales T, Clark BR, Gibb G, Reynolds CH, Kellie S, Bird IN, Varndell IM, Sheppard PW, Everall I, Anderton BH: Rapid tyrosine phosphorylation of neuronal proteins including tau and focal adhesion kinase in response to amyloid-beta peptide exposure: involvement of Src family protein kinases. I Neurosci 2002, 22(I): 10-20.

19. Patil S, Chan C: Palmitic and stearic fatty acids induce Alzheimer-like hyperphosphorylation of tau in primary rat cortical neurons. Neurosci Lett 2005, 384(3):288-293.

20. Patil S, Sheng L, Masserang A, Chan C: Palmitic acid-treated astrocytes induce BACEI upregulation and accumulation of C-terminal fragment of APP in primary cortical neurons. Neurosci Lett 2006, 406( (1-2):55-59.

21. Patil S, Melrose J, Chan C: Involvement of astroglial ceramide in palmitic acid-induced Alzheimer-like changes in primary neurons. Eur J Neurosci 2007, 26(8):2|3|-2|4|.

22. Blazquez C, Galve-Roperh I, Guzman M: De novo-synthesized ceramide signals apoptosis in astrocytes via extracellular signal-regulated kinase. Faseb ] 2000, I 4( I 4):23 | 5-2322.

23. Szutowicz A, Lysiak W: Regional and subcellular distribution of ATP-citrate lyase and other enzymes of acetyl-CoA metabolism in rat brain. J Neurochem 1980, 35(4):775-785.

24. Pei Z, Oey NA, Zuidervaart MM, Jia Z, Li Y, Steinberg SJ, Smith KD, Watkins PA: The acyl-CoA synthetase "bubblegum" (lipidosin): further characterization and role in neuronal fatty acid beta-oxidation. J Biol Chem 2003, 278(47):47070-47078.

25. Bearer CF, Swick AR, O'Riordan MA, Cheng G: Ethanol inhibits LI-mediated neurite outgrowth in postnatal rat cerebellar granule cells. J Biol Chem I999, 274( I 9): I 3264- I 3270.
Publish with BioMed Central and every scientist can read your work free of charge

"BioMed Central will be the most significant development for disseminating the results of biomedical research in our lifetime. "

Sir Paul Nurse, Cancer Research UK

Your research papers will be:

- available free of charge to the entire biomedical community

- peer reviewed and published immediately upon acceptance

- cited in PubMed and archived on PubMed Central

- yours - you keep the copyright
BioMedcentral 